Zhen An*, Jinshan Li, Yong Feng, Xianghong Liu and Yuxuan Du

\title{
Characterization of Hot Deformation Behavior of a New Near- $\beta$ Titanium Alloy: Ti555211
}

DOI 10.1515/htmp-2015-0097

Received June 30, 2015; accepted October 3, 2015

\begin{abstract}
The deformation behavior of an isothermally compressed Ti555211 titanium alloy was examined by an Arrhenius-type constitutive model using experimental data obtained from hot compression tests; these tests were performed at temperatures and strain rates of 750 $950^{\circ} \mathrm{C}$ and $0.001-1 \mathrm{~s}^{-1}$, respectively. Activation energies of hot deformation were calculated in 0.05 intervals for strains ranging from 0.1 to 0.7 . The respective values of were obtained for the $(\alpha+\beta)$ and $\beta$ region. In addition, the predictive capability of the model was described by the average absolute relative error (AARE) and the correlation coefficient $(R)$. The simulated values were compared with the experimental values, and $R$ and AARE of 0.99084 and $6.914 \%$, respectively, were obtained for the Arrheniustype constitutive model. These values were indicative of the good predictive capabilities of the developed straincompensated constitutive equation. Moreover, in this work isothermal compression tests, scanning electron microscopy (SEM), electron backscatter diffraction (EBSD), and transmission electron microscopy (TEM) were used to systematically investigate the high-temperature deformation behavior of Ti555211 alloy under different processing conditions. EBSD and TEM were used to reveal the substructure and grain orientation of samples of the hot-deformed Ti555211 alloy. The phenomenon of discontinuous yielding was also discussed.
\end{abstract}

Keywords: Ti555211 titanium alloy, high temperature, deformation behavior

*Corresponding author: Zhen An, State Key Laboratory of Solidification Processing, Northwestern Polytechnical University, Xi'an 710072, China, E-mail: anzhen1016@163.com

Jinshan Li, State Key Laboratory of Solidification Processing, Northwestern Polytechnical University, Xi'an 710072, China Yong Feng, State Key Laboratory of Solidification Processing, Northwestern Polytechnical University, Xi'an 710072, China; Western Superconducting Technologies Co., Ltd., Xi'an 710018, China Xianghong Liu, Yuxuan Du, Western Superconducting Technologies Co., Ltd., Xi'an 710018, China
Introduction

Near- $\beta$ titanium alloys, such as Ti-10V-2Fe-3Al, Ti-5Al5Mo-5V-3Cr and Ti-5Al-5Mo-5V-3Cr-1Zr, are lightweight and easily processed and have excellent mechanical properties [1-4]. These alloys have, therefore, been used extensively in the aerospace and chemical process industries [5-7]. During the hot deformation process, the material flow behavior is highly complex and nonlinear due to the many factors that influence the flow stress of materials. In fact, microstructural evolution of the near$\beta$ titanium alloys varies with processing parameters such as the deformation temperature, strain rate, and strain.

Therefore, a fundamental understanding of the influence of processing parameters on the deformation characteristics of these alloys is essential to process optimization and control of the microstructural evolution during hot deformation processing. Many studies have been conducted on the high-temperature deformation behavior and microstructure evolution of various near- $\beta$ titanium alloys, particularly Ti-5553, Ti55531, and Ti-1023. For example, Jackson et al. [8] examined the influence of initial microstructure on the flow behavior during isothermal forging of a Ti-1023 alloy, and found that the flow behavior was highly dependent on the original morphology of the $\alpha$ phase. In addition, Jones et al. [3, 4, 9] investigated the microstructural evolution and flow behavior during subtransus isothermal forging of Ti-5Al-5Mo-5V-3Cr alloy; three different initial microstructures were examined, and the initial flow behavior and main deformation mechanism were found to depend on the morphology and volume fraction of the $\alpha$ precipitates. Zhao et al. [10] determined the hot deformation characteristics of a Ti-1300 alloy, a new near- $\beta$ titanium alloy, for processing at temperatures and strain rates of $920-1010^{\circ} \mathrm{C}$ and $0.01-10 \mathrm{~s}^{-1}$, respectively. Using electron backscatter diffraction (EBSD), Warchomicka et al. [11] studied the hot deformation behavior of Ti-55531 alloy and found that deformation parameters had a significant influence on the grain boundary character, grain orientation, and occurrence of dynamic recrystallization (DRX). 


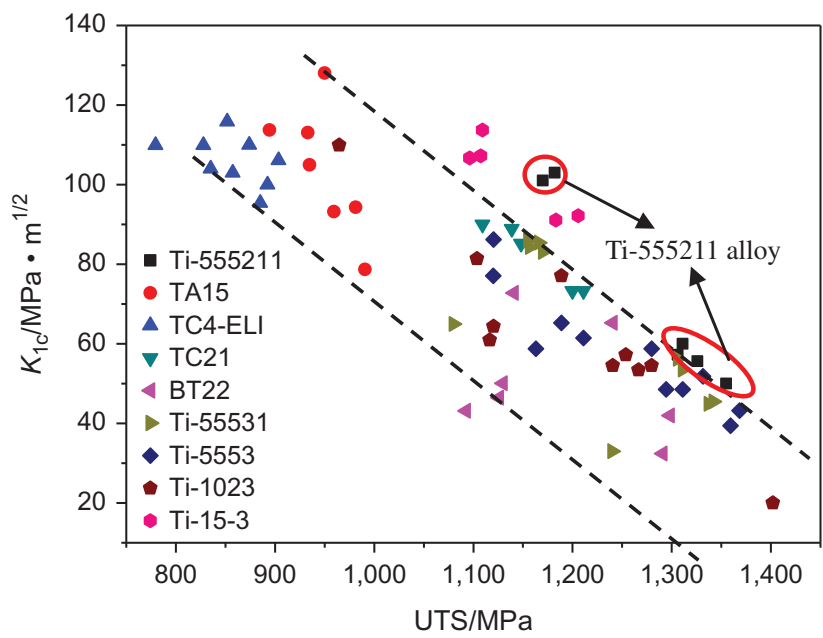

Figure 1: Dependence of the fracture toughness on the tensile strength of similar titanium alloys (Ti-5553 [13, 14], Ti-1023 [15, 16], BT22 [17], Ti-15-3 [18], TC21 [19], TC4-ELI [20], and TA15 [21, 22]).

Ti555211 titanium alloy is a new near- $\beta$ titanium alloy [12]. The dependence of fracture toughness on tensile strength of similar titanium alloys, such as Ti-555211, Ti-5553, Ti-55531, Ti-1023, BT22, Ti-15-3, TC21, TC4-ELI, and TA15 [13-22], is shown in Figure 1. As the figure shows, the toughness depends linearly, in general, on the strength; for example, Ti-555211 alloy has a high tensile strength and correspondingly high fracture toughness, indicating that this alloy has excellent mechanical properties and is highly competitive. Further research is required, however, for an in-depth understanding of the high-temperature deformation behavior of this promising alloy. Minimal research has been conducted on its flow stress behavior and deformation characteristics and their relationship during high-temperature deformation. Moreover, there are only a few studies that include both EBSD and transmission electron microscopy (TEM) analyses of near- $\beta$ titanium alloys. As such, in this study, we determine the high-temperature deformation characteristics of Ti555211 alloy in order to formulate its constitutive relationship model, which incorporates the effect of strain and microstructural evolution.

In this study, isothermal compression tests, scanning electron microscopy (SEM), EBSD, and TEM were used to systematically investigate the high-temperature deformation behavior of Ti555211 alloy under various processing conditions.

\section{Materials and experiment}

Ti555211 titanium alloy was provided by Western Superconducting Technologies Co. Ltd. (People’s Republic
Table 1: Chemical composition (in wt.\%) of Ti555211 titanium alloy.

\begin{tabular}{lrrrrrrl}
\hline Al & Mo & V & Nb & Fe & Zr & 0 & Ti \\
\hline 5.52 & 5.11 & 4.95 & 2.08 & 1.02 & 1.12 & 0.11 & Balance \\
\hline
\end{tabular}

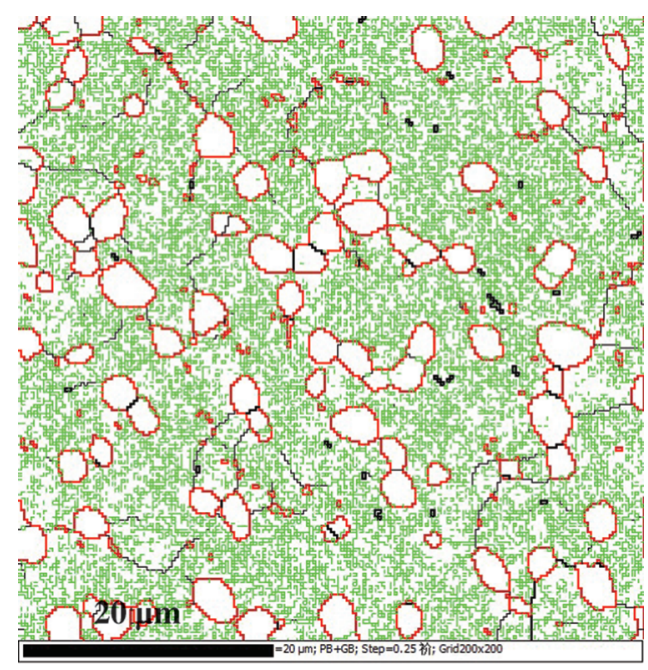

Figure 2: EBSD map showing the microstructure of the initial Ti555211 alloy.

of China). The composition of the alloy used in the present investigation is given in Table 1.

The EBSD map of the initial microstructure (Figure 2) shows that Ti555211 alloy consists of a small (i.e., 3-5 $\mu \mathrm{m}$ sized) globular primary $\alpha$ phase and an intergranular $\beta$ phase. Quantifying the types of grain boundaries present in the alloy is essential to describing the hot deformation behavior. Severe deformation results in orientation gradients or variations in the orientation and leads possibly to blurring of the grain boundaries. Boundaries with misorientation angles of $2-5^{\circ}, 5-15^{\circ}$, and $>15^{\circ}$ are referred to as subgrain boundaries, low-angle grain boundaries (LAGBs), and high-angle grain boundaries (HAGBs), respectively; these are denoted by the respective thin green, thin black, and thick black solid lines in Figure 3. The distribution of misorientation angles in the initial microstructure (Figures 2 and 3) reveals that almost all of the boundaries are subgrain boundaries and LAGBs.

In this paper, the small samples of $\Phi 8^{\star} 12 \mathrm{~mm}$ were cut from a $\Phi 250 \mathrm{~mm}$ Ti-555211 alloy billet bar. The processing of the bar consisted of vacuum arc remelting and forging at about $1,200^{\circ} \mathrm{C}$ to break down the as-cast microstructures, and a final forging at about $835^{\circ} \mathrm{C}$. The $\beta$ transus temperature of Ti555211 alloy determined by metallographic observations was approximately $875-880^{\circ} \mathrm{C}$. Hot compression experiments were conducted under isothermal conditions 

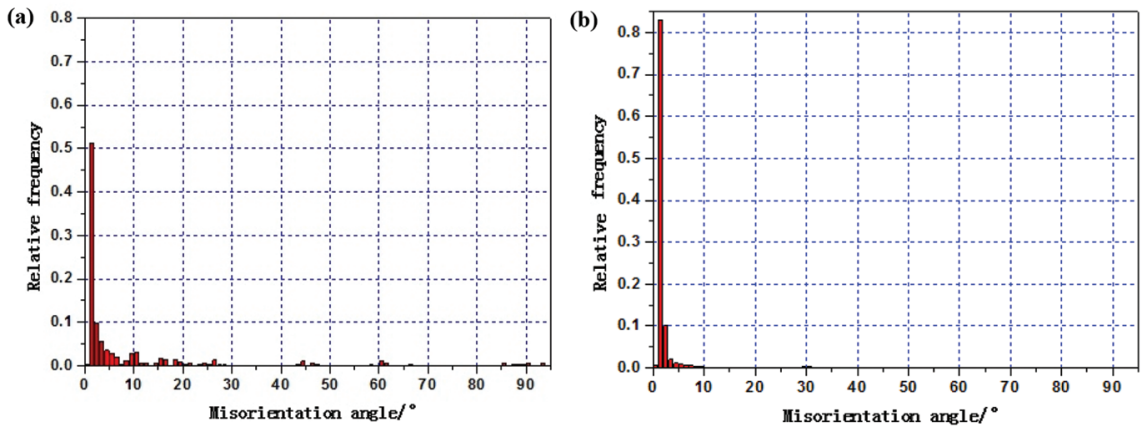

Figure 3: Distribution of grain boundary misorientation angles (the initial microstructure): (a) $\alpha$ phase; (b) $\beta$ phase. at temperatures of $750-950^{\circ} \mathrm{C}$ and true strain rates of 0.001 , $0.01,0.1$, and $1 \mathrm{~s}^{-1}$; the temperature was increased in $50^{\circ}$ intervals. A Gleeble-3800 machine was used to perform the tests. The specimens were all heated to the deformation temperature at a rate of $20^{\circ} \mathrm{C} / \mathrm{min}$, and held for $3 \mathrm{~min}$, before the commencement of high-temperature deformation, in order to achieve a homogeneous temperature field. Furthermore, two pieces of thin tantalum sheets were placed between the high-temperature compression specimen and the die to reduce friction and maintain uniform deformation. The samples were all deformed up to $50 \%$ reduction and immediately cooled in water in order to retain the deformed microstructures. The deformed specimens were cut longitudinally and mechanically ground using grit papers with particle sizes ranging from $80 \#$ to 2000\# mesh. The microstructure of each specimen was examined with an OLYMPUS/GX51 optical microscope and a JSM-6460 SEM. In order to achieve the surface quality required for EBSD examination, the samples were electropolished for $60 \mathrm{~s}$ at $20^{\circ} \mathrm{C}$ with a solution of $10 \%$ perchloric acid and $90 \%$ alcohol, using a voltage of $35 \mathrm{~V}$. The prepared samples were analyzed in a ZEISS SUPRA55-SEM operated at $20 \mathrm{kV}$ and equipped with a Nordlys EBSD detector; the TSL OIM EBSD (EDAX, New Jersey, USA) software was used to analyze the orientation data and determine the grain boundary type. TEM observations were made on the JEM-2010 TEM operated at $160 \mathrm{kV}$. The specimens used for TEM examination were prepared by ion milling at $4 \mathrm{keV}$.

\section{Results and discussion}

\section{Flow behavior}

The typical stress-strain curves obtained at $750^{\circ} \mathrm{C}$, $800^{\circ} \mathrm{C}, 850^{\circ} \mathrm{C}, 900^{\circ} \mathrm{C}$, and $950^{\circ} \mathrm{C}$ and different strain rates are shown in Figure 4. These curves exhibit the following characteristics:
(1) Three distinct stages of stress evolution with strain. Work hardening (WH) plays an important role in the deformation in the first stage, and the flow stress increases rapidly to a critical value [5]. The curve has a very large slope, and the material deforms mainly by WH and dynamic recovery (DRV).

(2) In the second stage, the increase in the flow stress slows until a peak value or an inflection of work-hardening rate is reached, which indicates that the thermal softening due to DRX and DRV exceeds WH [5].

(3) The curves are gradually stabilized in the third stage and exhibit flow softening phenomena and steadily decreasing flow characteristics.

(4) High strain rates result in discontinuous yielding at some of the experimental temperatures. The severity of this yielding increases with increasing deformation temperature.

\section{The phenomenon of discontinuous yielding}

In the initial stages of deformation, the material deforms primarily by the cross slip of dislocations, which is the main softening mechanism operating during the hightemperature plastic deformation of metals. The hardening that results from increasing dislocation density is substantially larger than the dynamic softening stemming from cross slip and therefore, the flow stress increases significantly with increasing strain. When the flow stress reaches the peak stress, the vacancy concentration of the material increases with increasing strain, and subsequent softening results from dislocation climb in the mid and late stages of deformation. Moreover, the steady-flow stage begins when a dynamic equilibrium between hardening and softening mechanisms is reached [23-27].

The steady-state deformation mechanism encompasses the proliferation of dislocation and the interaction of different numbers of dislocation. The dynamic theories can be used to explain the phenomenon of discontinuous yielding. 

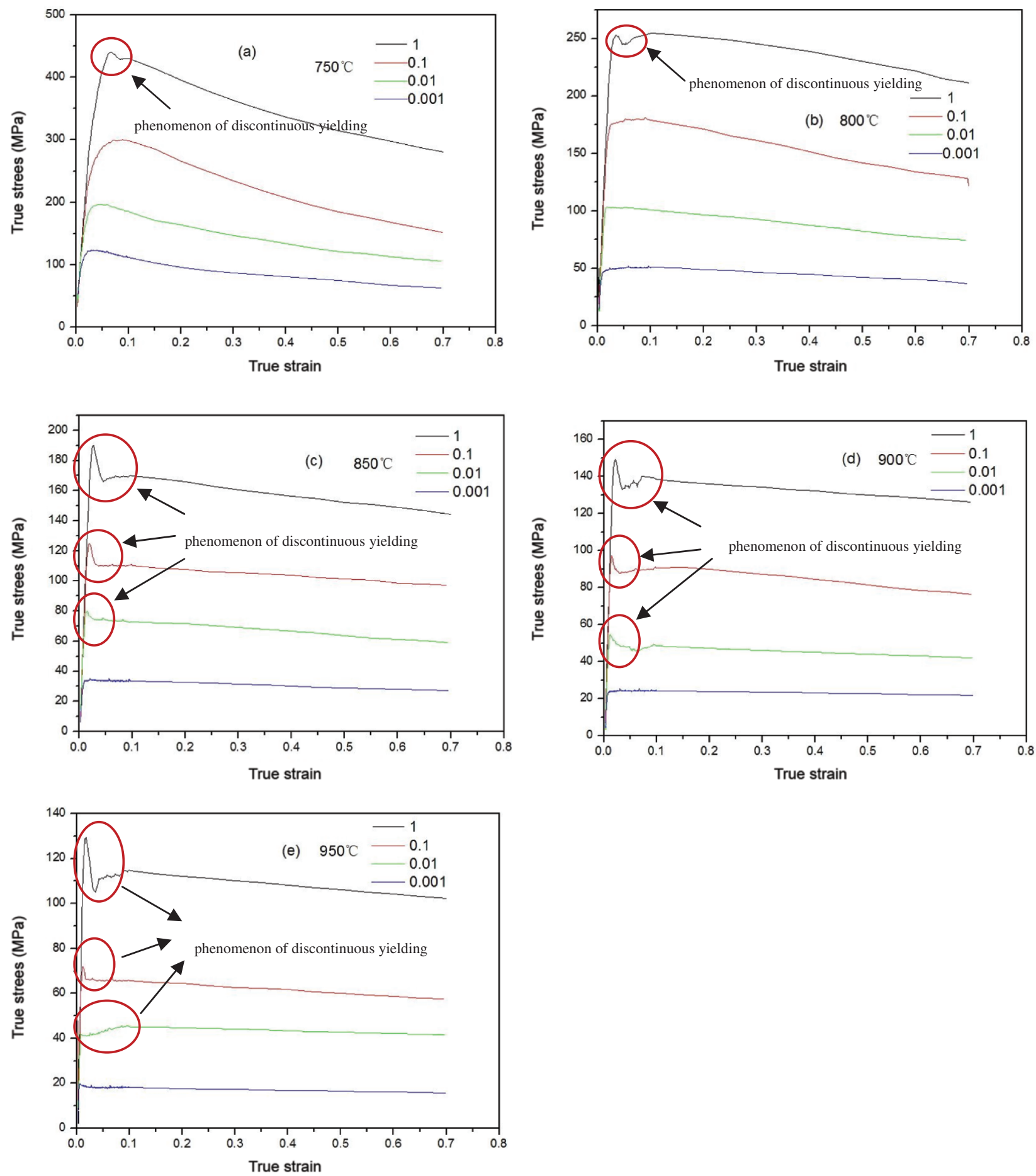

Figure 4: True stress-true strain curves of Ti555211 alloy: (a) $750^{\circ} \mathrm{C}$; and (b) $800^{\circ} \mathrm{C}$; (c) $850^{\circ} \mathrm{C}$; (d) $900^{\circ} \mathrm{C}$; (e) $950^{\circ} \mathrm{C}$.

A high density of mobile dislocations is generated in the grain boundaries during deformation. However, these dislocations are hindered by the boundaries, thereby resulting in a sharp increase in the flow stress. Subsequent dislocation climb into the interior of the grain boundaries results in significant dislocation annihilation, which in turn leads to discontinuous yielding when some critical dislocation density is reached [24-27]. Therefore, pronounced discontinuous yielding occurs at high strain rates. Discontinuous yielding of Ti555211 titanium alloy during high-temperature deformation is well-explained by the dislocation dynamics theory. 
Weiss and Semiatin [28] reported that discontinuous yielding during the hot deformation of Ti-15v-3Al$3 \mathrm{Cr}-3 \mathrm{Sn}$ alloy resulted from the multiplication of mobile dislocations. Philinpart observed similar trends via TEM analysis of the microstructural evolution of Ti-6.5Mo4.5Fe-1.5Al alloy. As Figure 5 shows, the grain boundaries are hindered by the high density of dislocations generated therein. Moreover, the amount of DRV in the $\beta$ phase increases significantly when the dislocation density reaches some critical value, thereby resulting in a significant decrease in the flow stress; this decrease confirms the occurrence of discontinuous yielding.

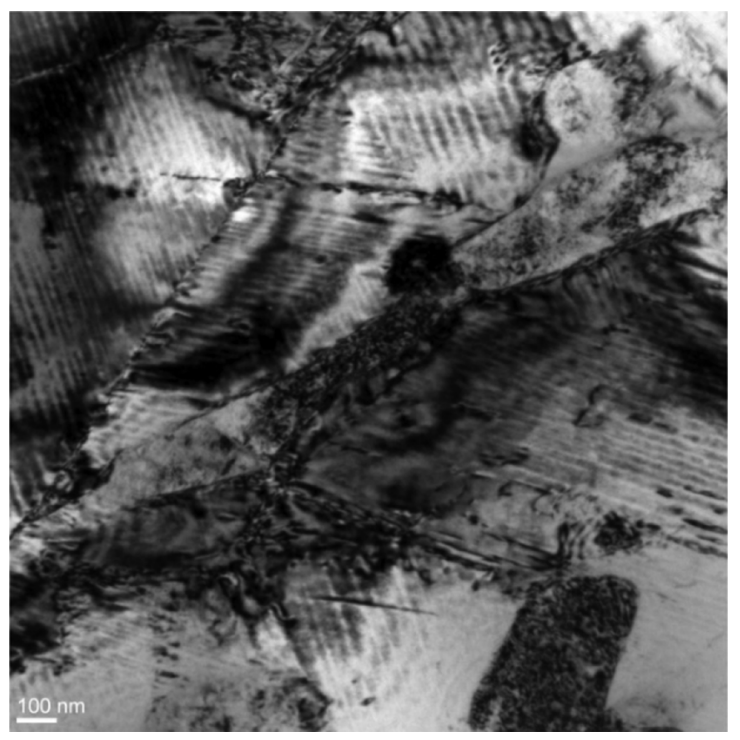

Figure 5: Micrograph showing grain boundary dislocation generation in Ti555211 alloy deformed at $950^{\circ} \mathrm{C}$ and $1 \mathrm{~s}^{-1}$ to a true strain of 0.02 .

\section{Constitutive relationship model considering the effect of strain}

The classical relationship can be generally expressed as an Arrhenius equation. Furthermore, the effect of the strain rate and temperature on the deformation behavior can be expressed as a Zener-Hollomon parameter exponent-type equation. The Arrhenius hyperbolic equation provides a good fit for the flow stress and ZenerHollomon parameter.

$$
\begin{gathered}
Z=\dot{\varepsilon} \exp \left(\frac{Q}{R T}\right) \\
\dot{\varepsilon}=A F(\sigma) \exp \left(-\frac{Q}{R T}\right)
\end{gathered}
$$

$$
F(\sigma)=\left\{\begin{array}{cc}
\sigma^{n} & \alpha \sigma<0.8 \\
\exp (\beta \sigma) & \alpha \sigma>1.2 \\
\sinh (\alpha \sigma) & \text { for all } \sigma
\end{array}\right.
$$

where $A, \alpha$, and $n$ are the material constants, $\alpha=\beta / n ; \sigma, Q, R$, $T, Z$, and $\dot{\varepsilon}$ are the true stress, activation energy of hot deformation $\left(\mathrm{kJ} \mathrm{mol}^{-1}\right)$, universal gas constant $(8.31 \mathrm{~J}$ $\mathrm{mol}^{-1} \mathrm{~K}^{-1}$ ), absolute temperature (K), Zener-Hollomon parameter, and strain rate $\left(\mathrm{s}^{-1}\right)$, respectively.

\section{Determination of material constants for Arrhenius-type constitutive relationship}

The influence of the strain on the stress is typically not considered in eqs (1) and (2). Therefore, an Arrheniustype constitutive relationship that includes strain compensation is established in order to determine the effect of strain on the flow stress. The corresponding material constants can be evaluated from the stress-strain curves resulting from the compression tests. The material constants are determined at a deformation strain of 0.1 as follows.

At low and high stress levels, the power law and exponential law are substituted for $F(\sigma)$ in eq. (2) and the strain rates are then obtained from

$$
\begin{gathered}
\dot{\varepsilon}=B \sigma^{n_{1}} \\
\dot{\varepsilon}=C \exp (\beta \sigma)
\end{gathered}
$$

where $B$ and $C$ are the material constants, which are independent of the deformation temperature.

Taking the logarithm of both sides of eqs (4) and (5) gives

$$
\begin{gathered}
\ln (\sigma)=\frac{1}{n_{1}} \ln (\dot{\varepsilon})-\frac{1}{n_{1}} \ln (B) \\
\sigma=\frac{1}{\beta} \ln (\dot{\varepsilon})-\frac{1}{\beta} \ln (C)
\end{gathered}
$$

However, the final microstructure after deformation at temperatures of $875^{\circ} \mathrm{C}$ or higher consisted of only $\beta$ grains. Therefore, the relevant material constants should be calculated separately for the $\alpha+\beta$ phase and the single $\beta$ phase.

The values of $\beta$ and $n_{1}$ can be determined from the slope of the lines in the plot of $\sigma-\ln \dot{\varepsilon}$ and $\ln \sigma-\ln \dot{\varepsilon}$. The slope of the lines in Figures 6(a), 6(b), 7(a), and 7(b) changed only slightly. At a deformation strain of $0.1, \beta$ and $n_{1}$ were computed as $0.035509(\alpha+\beta$ phase $)$ and $3.12467(\alpha+\beta$ phase $) / 0.0670552$ ( $\beta$ phase $)$ and $2.85447(\beta$ phase) in Figures 6 and 7. 
(a)

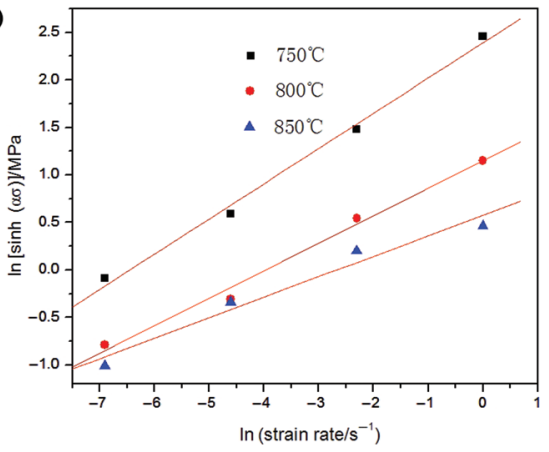

(c)

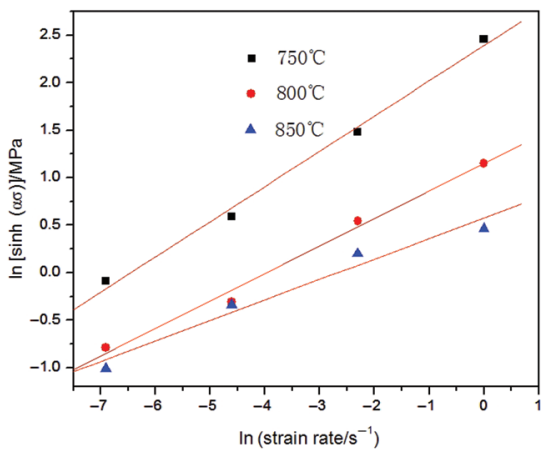

(a)

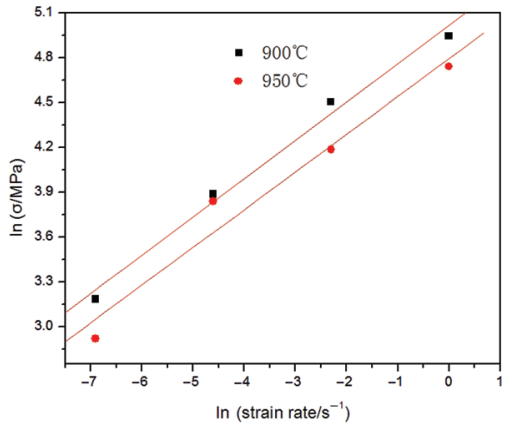

(c)

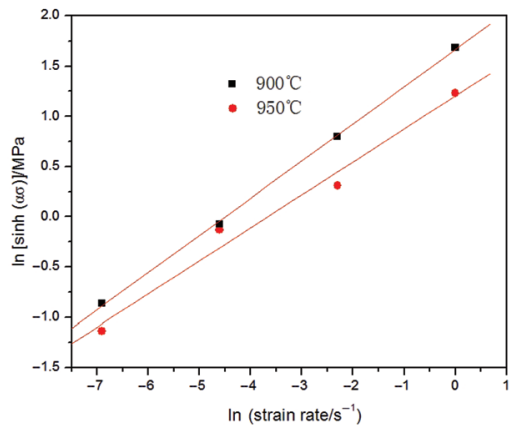

(b)

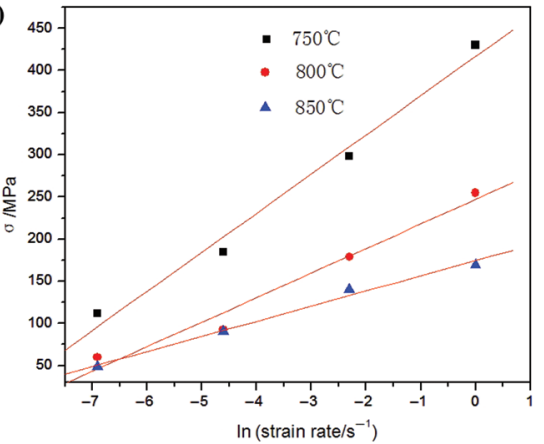

(d)

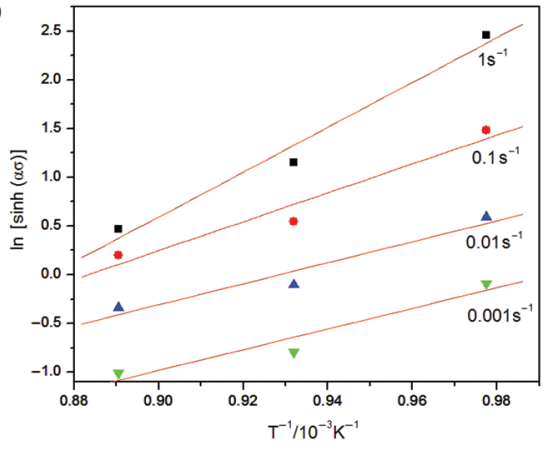

Figure 6: Relationship between (a) In $\sigma$ and $\ln \dot{\varepsilon}$; (b) $\sigma$ and $\ln \dot{\varepsilon}$; (c) $\ln [\sinh$ $(\alpha \sigma)]$ and $\ln \dot{\varepsilon} ;(d) \ln [\sinh (\alpha \sigma)]$ and $T^{-1} / 10^{-3} K^{-1}$ for $\alpha+\beta$ phase.

(b)

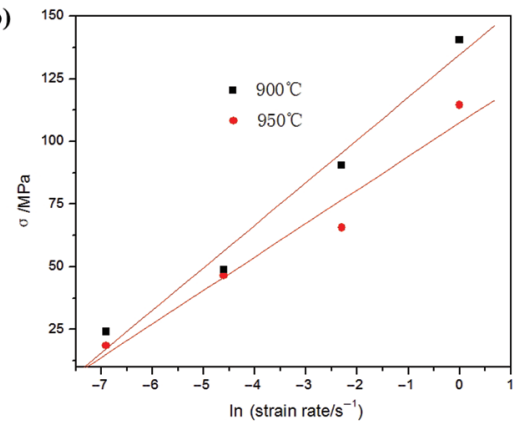

(d)

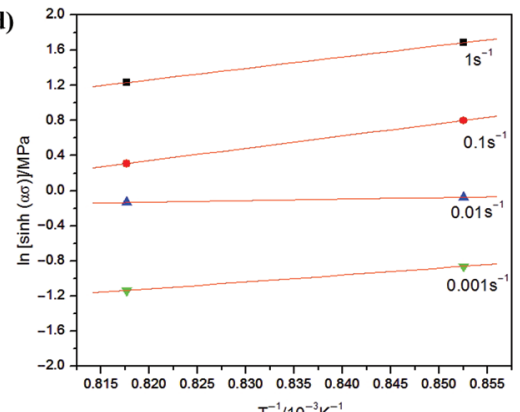

Figure 7: Relationship between (a) In $\sigma$ and $\ln \dot{\varepsilon}$; (b) $\sigma$ and $\ln \dot{\varepsilon}$; (c) $\ln [\sinh$ $(\alpha \sigma)]$ and $\ln \dot{\varepsilon} ;(\mathrm{d}) \ln [\sinh (\alpha \sigma)]$ and $T^{-1} / 10^{-3} \mathrm{~K}^{-1}$ for $\beta$ phase.
Therefore, $\alpha=\beta / n_{1}=0.00797 \mathrm{MPa}^{-1}(\alpha+\beta$ phase $) / 0.0171605$ $\mathrm{MPa}^{-1}(\beta$ phase).

Equation (2) can then be rewritten as

$$
\dot{\varepsilon}=A[\sinh (\alpha \sigma)]^{n} \exp \left(-\frac{Q}{T R}\right)
$$

Taking the logarithm of both sides of eq. (8) gives

$$
\begin{gathered}
\ln [\sinh (\alpha \sigma)]=\frac{\ln \dot{\varepsilon}}{n}+\frac{Q}{n T R}-\frac{\ln A}{n} \\
Q=R n \frac{d \ln [\sinh (\alpha \sigma)]}{d(1 / T)} \\
\mathrm{Z}=\mathrm{A}[\sinh (\alpha \sigma)]^{n}
\end{gathered}
$$

Taking the logarithm of both sides of eq. (11) gives: 


$$
\ln Z=\ln A+n \ln [\sinh (\alpha \sigma)]
$$

The flow stress can then be expressed as a function of the $Z$ parameter, i.e.,

$$
\sigma=\frac{1}{\alpha} \ln \left\{\left(\frac{Z}{A}\right)^{1 / n}+\left[\left(\frac{Z}{A}\right)^{2 / n}+1\right]^{1 / 2}\right\}
$$

The material constants $\ln A, n$, and $Q$ at a deformation strain of 0.1 can be determined by eqs (9-12). In addition, the regression analysis of eq. (12) and Figure 8 yields $\ln$ $A=48.84\left(\alpha+\beta\right.$ phase), $\ln A=18.23$ ( $\beta$ phase), $Q_{\text {ave }}=476.557$ $\mathrm{kJ} \mathrm{mol}{ }^{-1}(\alpha+\beta$ phase $), Q_{\mathrm{ave}}=222.173 \mathrm{~kJ} \mathrm{~mol}^{-1}(\beta$ phase $)$, $n=2.99194(\alpha+\beta$ phase $)$, and $n=2.82151$ ( $\beta$ phase $)$.

The material constants $(\alpha, n, Q$, and $A)$ are calculated from eqs (9-13), and the flow stress is determined from eq. (13). However, the effect of strain is neglected in this equation. In true stress-true strain curves, the flow stress exhibits a significant dependence on the strain, which is manifested as strain hardening and dynamic softening
$[29,30]$. Therefore, in order to accurately predict the flow stress, the effect of strain should be considered. The material constants $(a, n, Q$, and $A)$ in eq. (14) are typically considered strain dependent. Therefore, in this work, the material constants (i.e., $\alpha, A, n, Q$ ) are calculated in 0.05 intervals for strains ranging from 0.1 to 0.7 . As shown in the following equation, these constants can be fitted by a polynomial, in which the strain is a variable, i.e.,

$$
\begin{aligned}
& Q=D_{6} \varepsilon^{6}+D_{5} \varepsilon^{5}+D_{4} \varepsilon^{4}+D_{3} \varepsilon^{3}+D_{2} \varepsilon^{2}+D_{1} \varepsilon+D_{0} \\
& \alpha=F_{6} \varepsilon^{6}+F_{5} \varepsilon^{5}+F_{4} \varepsilon^{4}+F_{3} \varepsilon^{3}+F_{2} \varepsilon^{2}+F_{1} \varepsilon+F_{0} \\
& A=e^{\mathrm{G}_{6}} \varepsilon^{6}+\mathrm{G}_{5} \varepsilon^{5}+\mathrm{G}_{4} \varepsilon^{4}+\mathrm{G}_{3} \varepsilon^{3}+\mathrm{G}_{2} \varepsilon^{2}+\mathrm{G}_{1} \varepsilon+\mathrm{G}_{0} \\
& n=H_{6} \varepsilon^{6}+H_{5} \varepsilon^{5}+H_{4} \varepsilon^{4}+H_{3} \varepsilon^{3}+H_{2} \varepsilon^{2}+H_{1} \varepsilon+H_{0}
\end{aligned}
$$

where $D_{0}-D_{6}, F_{0}-F_{6}, G_{0}-G_{6}$, and $H_{0}-H_{6}$ are the coefficients of the polynomial.

A sixth-order polynomial accurately represents the influence of strain on the material constants (Figures 9 and 10). Some of the material constants $\left(n_{(\alpha+\beta}\right.$ phase); $Q_{(\beta}$
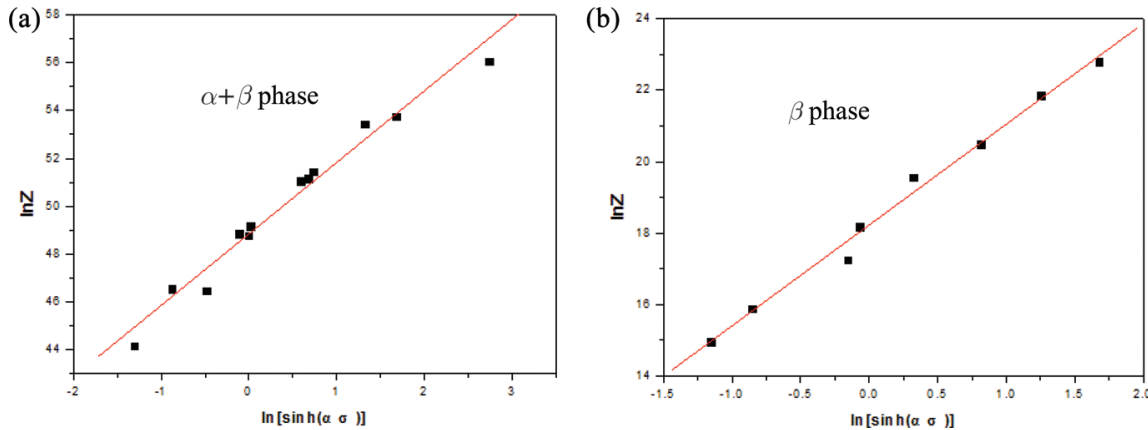

(a)

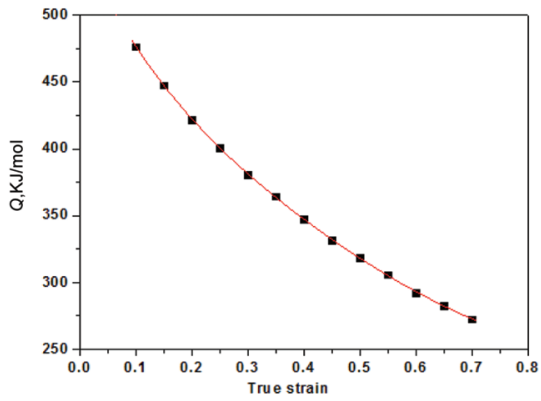

(c)

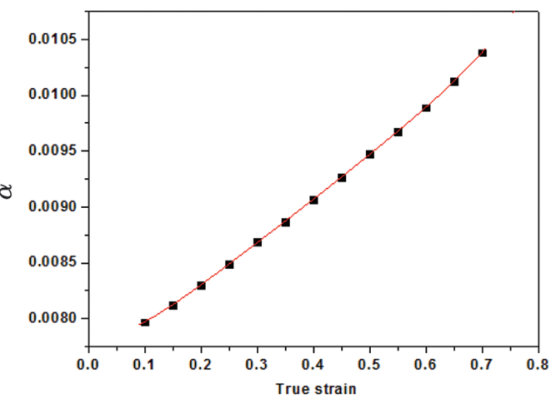

(b)

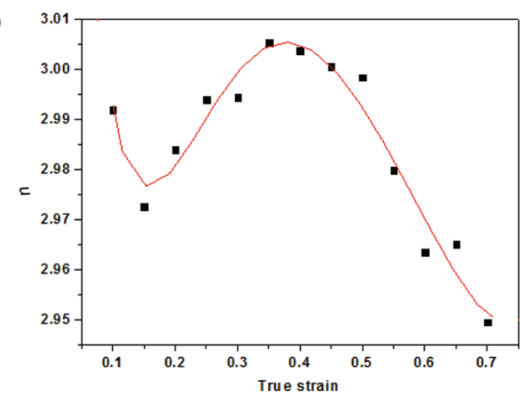

(d)

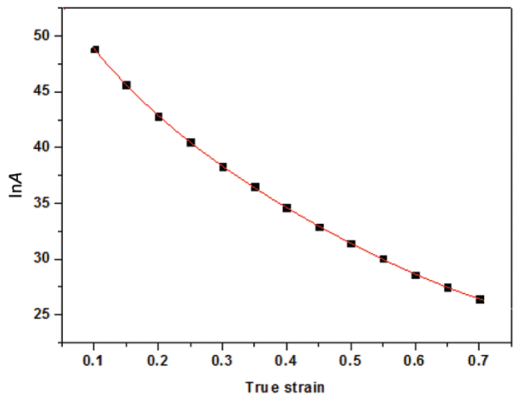

Figure 8: Relationship between $\ln Z$ and $\ln [\sinh (\alpha \sigma)]$ for (a) $\alpha+\beta$ phase; (b) $\beta$ phase.
Figure 9: Polynomial fit of relationships: (a) $Q$; (b) $n$; (c) $\alpha$; (d) $\ln A$; with strain for $\alpha+\beta$ phase. 
(a)

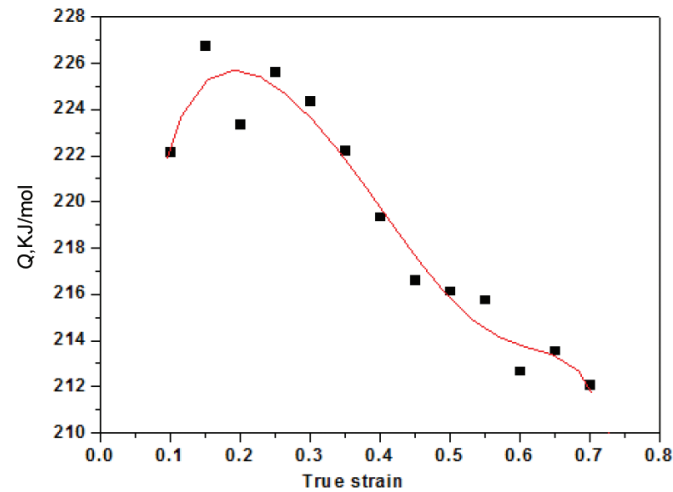

(c)

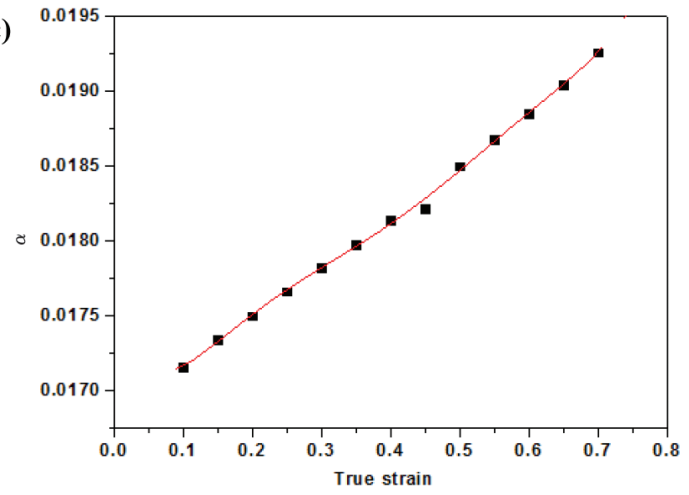

(b)

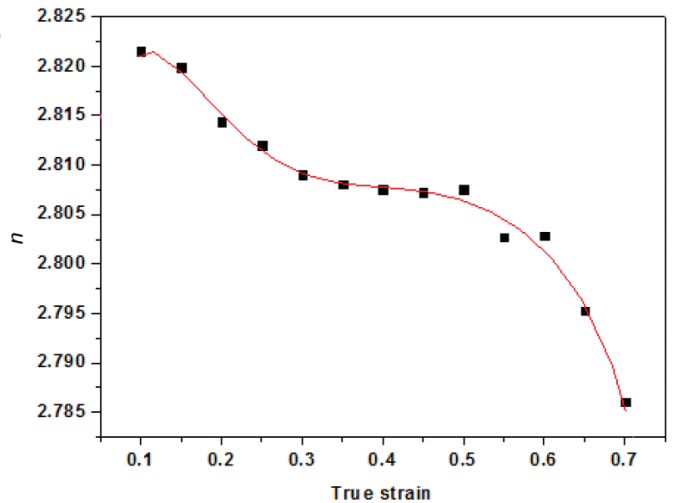

(d)

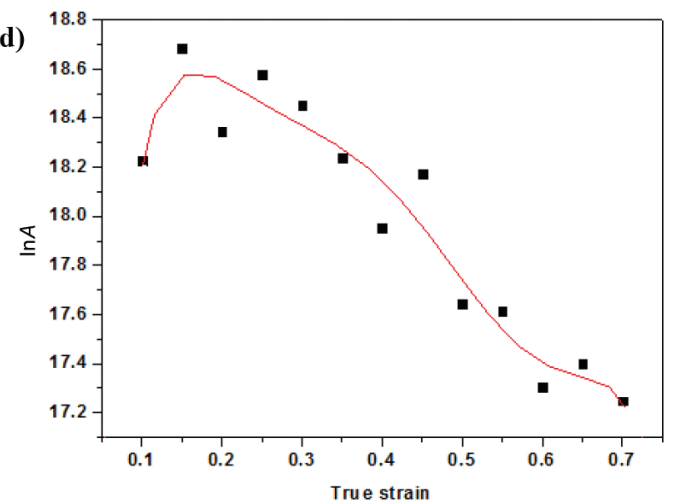

Figure 10: Polynomial fit of relationships: (a) $Q$; (b) $n$; (c) $\alpha$; (d) $\ln A$; with strain for $\beta$ phase.

phase); $n_{(\beta \text { phase); }} \ln A_{(\beta}$ phase) $)$ vary in a complex manner. Higher-order (i.e., $>6$ ) polynomials resulted in an over-fit, and hence the influence of strain was not accurately represented. However, lower-order (i.e., <6) polynomials exhibited insufficient fitting capacity and reflected the nature of the variables only somewhat. The results of the polynomial fit of $\alpha, n, Q$, and $\ln A$ of Ti555211 alloy are listed in Table 2 ( $\alpha+\beta$ phase) and Table 3 ( $\beta$ phase).

Table 2: Results of the polynomial fit of $Q, \alpha, \ln A$, and $n$ for the $\alpha+\beta$ phase.

\begin{tabular}{llll}
\hline$Q$ & $\alpha$ & $\ln A$ & $n$ \\
\hline$D_{0}=553.76948$ & $F_{0}=0.00784$ & $G_{0}=57.29243$ & $H_{0}=3.15221$ \\
$D_{1}=-930.91058$ & $F_{1}=-0.000872446$ & $G_{1}=-101.77048$ & $H_{1}=-3.08687$ \\
$D_{2}=1,862.55132$ & $F_{2}=0.02996$ & $G_{2}=202.5848$ & $H_{2}=19.66898$ \\
$D_{3}=-2,918.766$ & $F_{3}=-0.10252$ & $G_{3}=-329.01037$ & $H_{3}=-57.49236$ \\
$D_{4}=2,418.89475$ & $F_{4}=0.19676$ & $G_{4}=319.97452$ & $H_{4}=87.20392$ \\
$D_{5}=-667.34872$ & $F_{5}=-0.19849$ & $G_{5}=-165.26221$ & $H_{5}=-68.96821$ \\
$D_{6}=-80.48794$ & $F_{6}=0.0829$ & $G_{6}=41.6677$ & $H_{6}=22.91159$ \\
\hline
\end{tabular}

Table 3: Results of the polynomial fit of $Q, \alpha, \ln A$, and $n$ for the $\beta$ phase.

\begin{tabular}{llll}
\hline$Q$ & $\alpha$ & $\ln \boldsymbol{A}$ & $\boldsymbol{n}$ \\
\hline$D_{0}=202.15525$ & $F_{0}=0.01736$ & $G_{0}=13.95315$ & $H_{0}=2.79185$ \\
$D_{1}=375.32167$ & $F_{1}=-0.00964$ & $G_{1}=89.53075$ & $H_{1}=0.75068$ \\
$D_{2}=-2,371.40657$ & $F_{2}=0.11637$ & $G_{2}=-672.13406$ & $H_{2}=-6.619$ \\
$D_{3}=8,003.89099$ & $F_{3}=-0.49253$ & $G_{3}=2,520.29115$ & $H_{3}=25.31954$ \\
$D_{4}=-16,123.01192$ & $F_{4}=1.05187$ & $G_{4}=-5,054.43695$ & $H_{4}=-49.26467$ \\
$D_{5}=17,449.52169$ & $F_{5}=-1.09863$ & $G_{5}=5,118.44525$ & $H_{5}=48.19971$ \\
$D_{6}=-7,630.74978$ & $F_{6}=0.44757$ & $G_{6}=-2,049.88235$ & $H_{6}=-19.08359$ \\
\hline
\end{tabular}


The constitutive model considering the effect of strain is developed and the flow stress for all conditions can be calculated once the strain-compensated material constants are evaluated.

The constitutive equations describing the dependence of the flow stress of Ti555211 alloy on the strain rate and deformation temperature can be written as

$$
\begin{gathered}
\dot{\varepsilon}=A_{\alpha+\beta}\left[\sinh \left(\alpha_{\alpha+\beta} \sigma\right)\right]^{n_{\alpha+\beta}} \exp \left(-\frac{Q_{\alpha+\beta}}{T R}\right)(\alpha+\beta \text { phase }) \\
\dot{\varepsilon}=A_{\beta}\left[\sinh \left(\alpha_{\beta} \sigma\right)\right]^{n_{\beta}} \exp \left(-\frac{Q_{\beta}}{T R}\right)(\beta \text { phase })
\end{gathered}
$$

where $\alpha, n, Q$, and $A$ of Ti555211 alloy can be calculated by sixth-order polynomial (eq. (14)), and $D_{0}-D_{6}, F_{0}-F_{6}$, $G_{0}-G_{6}$, and $H_{0}-H_{6}$ listed in Table $2(\alpha+\beta$ phase $)$ and Table 3 ( $\beta$ phase) are the coefficients of the polynomial.

\section{Verification of the accuracy of the constitutive model considering the effect of strain}

As Figure 11 shows, the flow behavior of this material is accurately described by the predicted flow stress data for all experimental conditions except for $750^{\circ} \mathrm{C}, 1 \mathrm{~s}^{-1}$ and $850^{\circ} \mathrm{C}, 1 \mathrm{~s}^{-1}$; significant deviations occur between the experimental and predicted data for experimental conditions of $750^{\circ} \mathrm{C}, 1 \mathrm{~s}^{-1}$ and $850^{\circ} \mathrm{C}, 1 \mathrm{~s}^{-1}$. Phenomenological models based on physical theories of plastic deformation, although less rigorous than the polynomial method, make more accurate predictions for limited processing conditions where specific deformation mechanisms operate. In addition, DRX typically occurs at low strain rates. The extent of this recrystallization increases with decreasing strain rate. In contrast, bands of flow localization form and longitudinal cracking occurs at high strain rates $\left(\geq 1 \mathrm{~s}^{-1}\right)$. The difference in the deformation mechanisms operating at low and high strain rates may therefore lead to significant divergence between the predicted and experimental values, as observed in the case of $750^{\circ} \mathrm{C}$, $1 \mathrm{~s}^{-1}$ and $850^{\circ} \mathrm{C}, 1 \mathrm{~s}^{-1}$. Ji et al. [29] used a strain-compensated constitutive model to predict the high-temperature deformation behavior of AerMet100 steel; significant divergence occurred due to the difference in the physical mechanisms (cracking, shear bands, and twin kink bands vs. DRV and recrystallization, respectively) operating in the instability and stability regimes.

$$
R=\frac{\sum_{i=1}^{N}\left(E_{i}-\bar{E}\right)\left(P_{i}-\bar{P}\right)}{\sqrt{\sum_{i=1}^{N}\left(E_{i}-\bar{E}\right)^{2} \sum_{i=1}^{N}\left(P_{i}-\bar{P}\right)^{2}}}
$$

$$
\operatorname{AARE}(\%)=\frac{1}{N} \sum_{i=1}^{N}\left|\frac{E_{i}-P_{i}}{E_{i}}\right| \times 100
$$

The correlation coefficient $(R)$ is used to evaluate the accuracy of the predictions of the constitutive equation [30]. An $R$ of 0.99084 , as calculated from eq. (17) using the data plotted in Figure 12, reflects the excellent predictive capability of the developed constitutive equation. An AARE of $6.914 \%$ for the Arrhenius-type constitutive model is calculated from eq. (18).

\section{Microstructure evolution}

Figure 13 shows the microstructures resulting from isothermal compression $\left(\varepsilon=50 \%, \dot{\varepsilon}=0.001 \mathrm{~s}^{-1}\right)$ of Ti555211 alloy at different deformation temperatures. As Figure 13(a) and 13(b) shows, the primary $\alpha$ phase becomes increasingly equiaxed but its volume fraction increases only slightly with increasing deformation temperature of $750-800^{\circ} \mathrm{C}$. A portion of the secondary $\alpha$ phase is also dissolved and becomes globular. In addition, as Figure 13(c) shows, the morphology of the primary $\alpha$ phase is insensitive to the deformation temperature. However, the corresponding grain size and volume fraction decrease significantly. This decrease stems from partial transformation of the primary $\alpha$ phase to the $\beta$ phase, and the almost complete dissolution of the secondary $\alpha$ phase. At a deformation temperature of $900^{\circ} \mathrm{C}$ (Figure 13(d)), the primary $\alpha$ phase transformed completely to the $\beta$ phase, and only the $\beta$ grain boundaries are observed.

The deformation process (Figure 13(a)) is longer than all of the other processes and the elevated deformation temperatures significantly enhance the diffusion process. As such, the primary $\alpha$ phase consumes the nearby secondary $\alpha$ phase, thereby leading to the impingement of neighboring $\alpha$ grains [31-33]. Furthermore, the grain size is refined due to the transformation of primary and secondary $\alpha$ to the $\beta$ phase. The two mechanisms occur simultaneously, in general, but the mechanism governing the phase transition plays the dominant role when the deformation temperature is increased to a certain level [34].

Due to the small strain rate, the entire deformation process is longer than the other processes. Figure 13(d) shows that small DRX grains nucleated on the $\beta$ grain boundaries, and many elongated $\beta$ grains are present in the deformed microstructures; the new DRX grains are easily distinguished from the other microstructural features [35]. When the deformation temperature was 
(a)

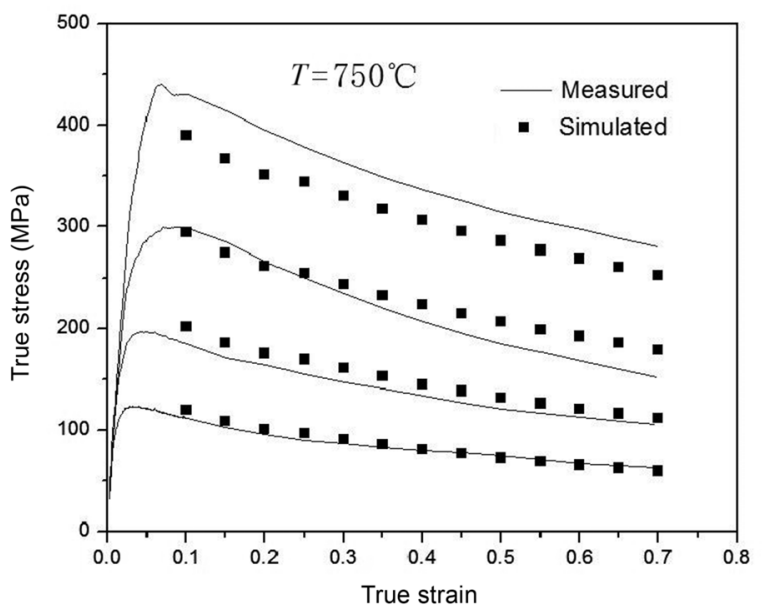

(c)

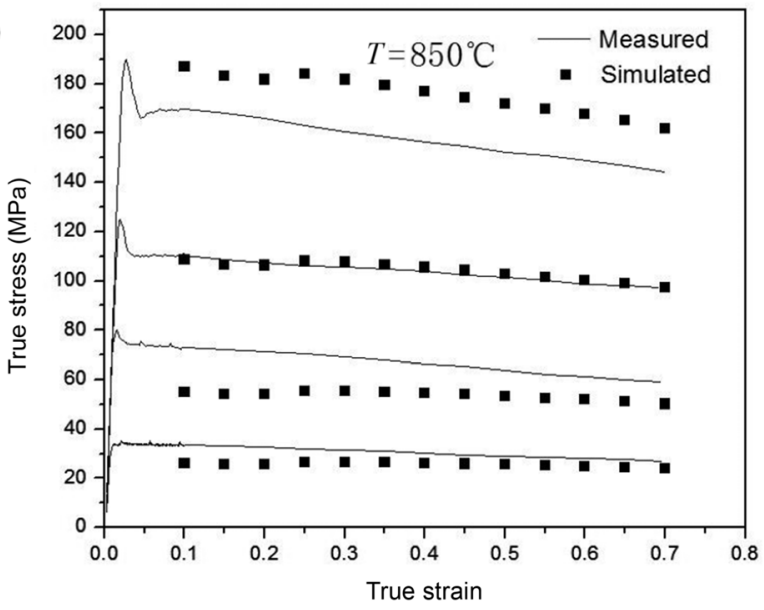

(b)

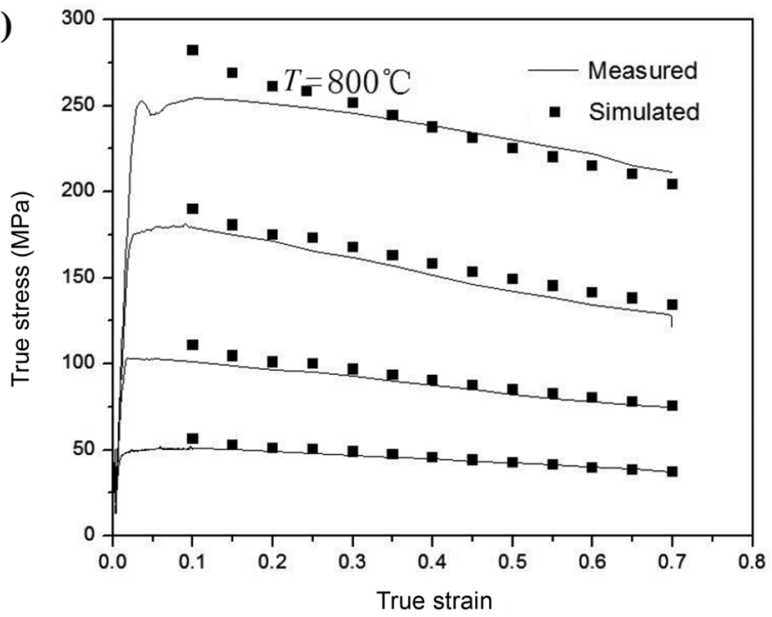

(d)

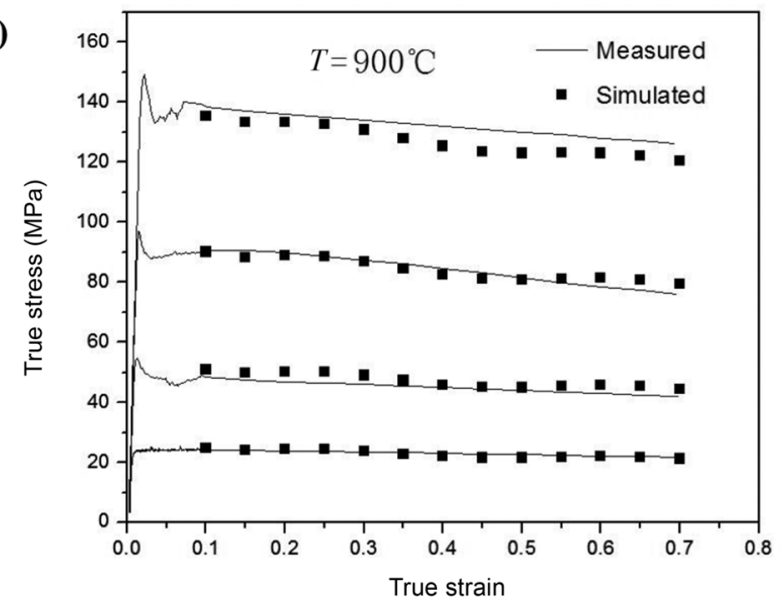

(e)

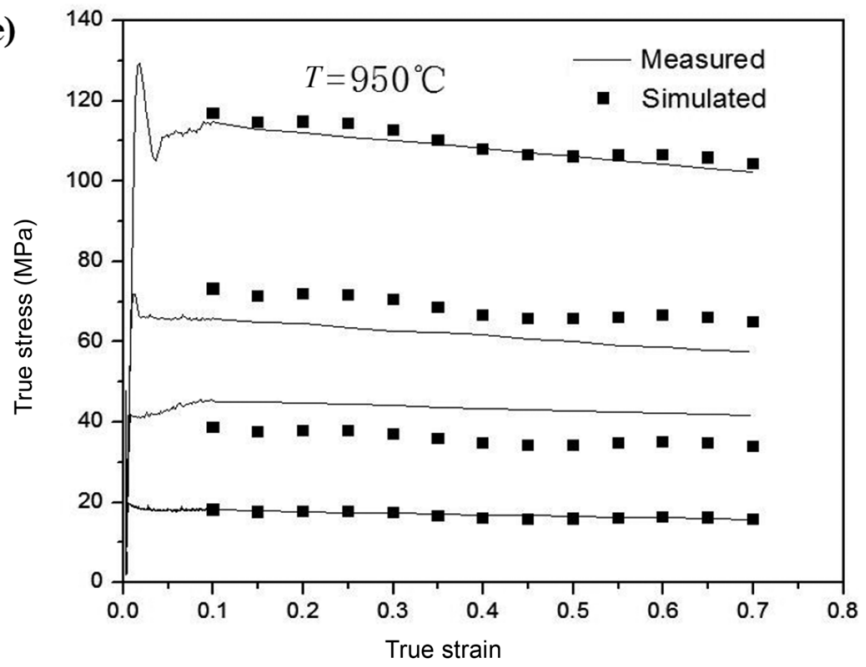

Figure 11: Comparison between the experimental and predicted flow stress at different temperatures: (a) $750^{\circ} \mathrm{C}$; (b) $800^{\circ} \mathrm{C}$; (c) $850^{\circ} \mathrm{C}$; (d) $900^{\circ} \mathrm{C}$ (e) $950^{\circ} \mathrm{C}$.

increased to $950^{\circ} \mathrm{C}$ (Figure 13(e)), the $\beta$ grains grew with serrated boundaries and fewer DRX $\beta$ grains were observed, compared to those at $900^{\circ} \mathrm{C}$. Moreover, the large $\beta$ grains consumed the neighboring small $\beta$ grains.
The deformation temperature has a significant effect on the morphology and volume fraction of the secondary $\alpha$ phase. For example, the volume fraction of the long rodlike secondary $\alpha$ phase decreases substantially when the 


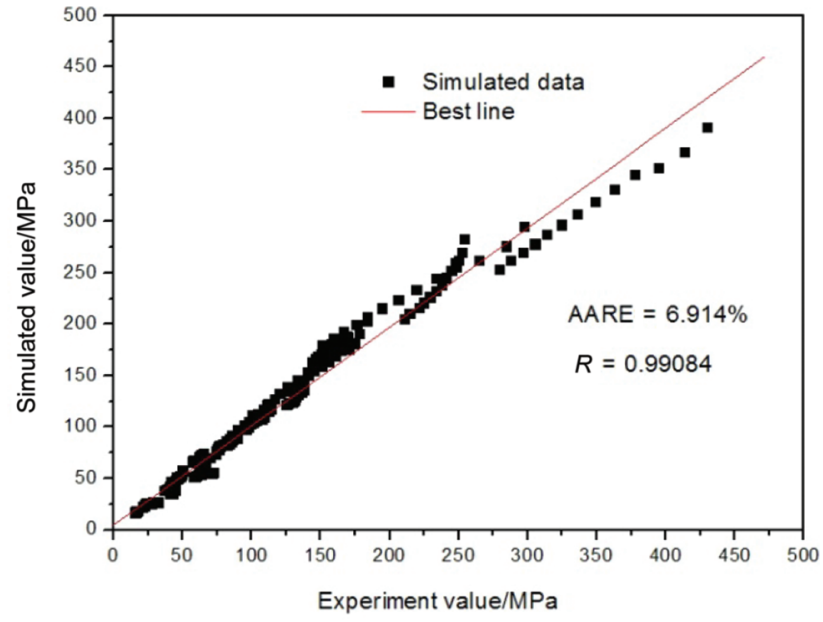

Figure 12: Comparison of the predicted data obtained from the Arrhenius-type constitutive model (taking the compensation of strain into account) and experimentally determined data. deformation temperature is increased from $750^{\circ} \mathrm{C}$ to $800^{\circ} \mathrm{C}$, where this phase exists mainly as short rod-like features. At $850^{\circ} \mathrm{C}$, the secondary $\alpha$ phase is no longer observed due to the phase transformation. Furthermore, for a given strain rate, the $\alpha$ phase is refined with increasing deformation temperature.

At a strain rate of $1 \mathrm{~s}^{-1}$, the microstructure (Figure 14) exhibits features which are typical of DRV. The volume fractions of primary and secondary $\alpha$ phase decrease due to the heat generated during deformation [36]. In addition, the temperature increase is strain rate dependent and hence, larger increases occur at high strain rates than at low ones. Crystal defects, such as dislocations, phase boundaries, and grain boundaries, constitute potential heterogeneous nucleation sites for the secondary $\alpha$ phase $[37,38]$. The density of these defects increases significantly with increasing strain rate, leading to precipitation of the
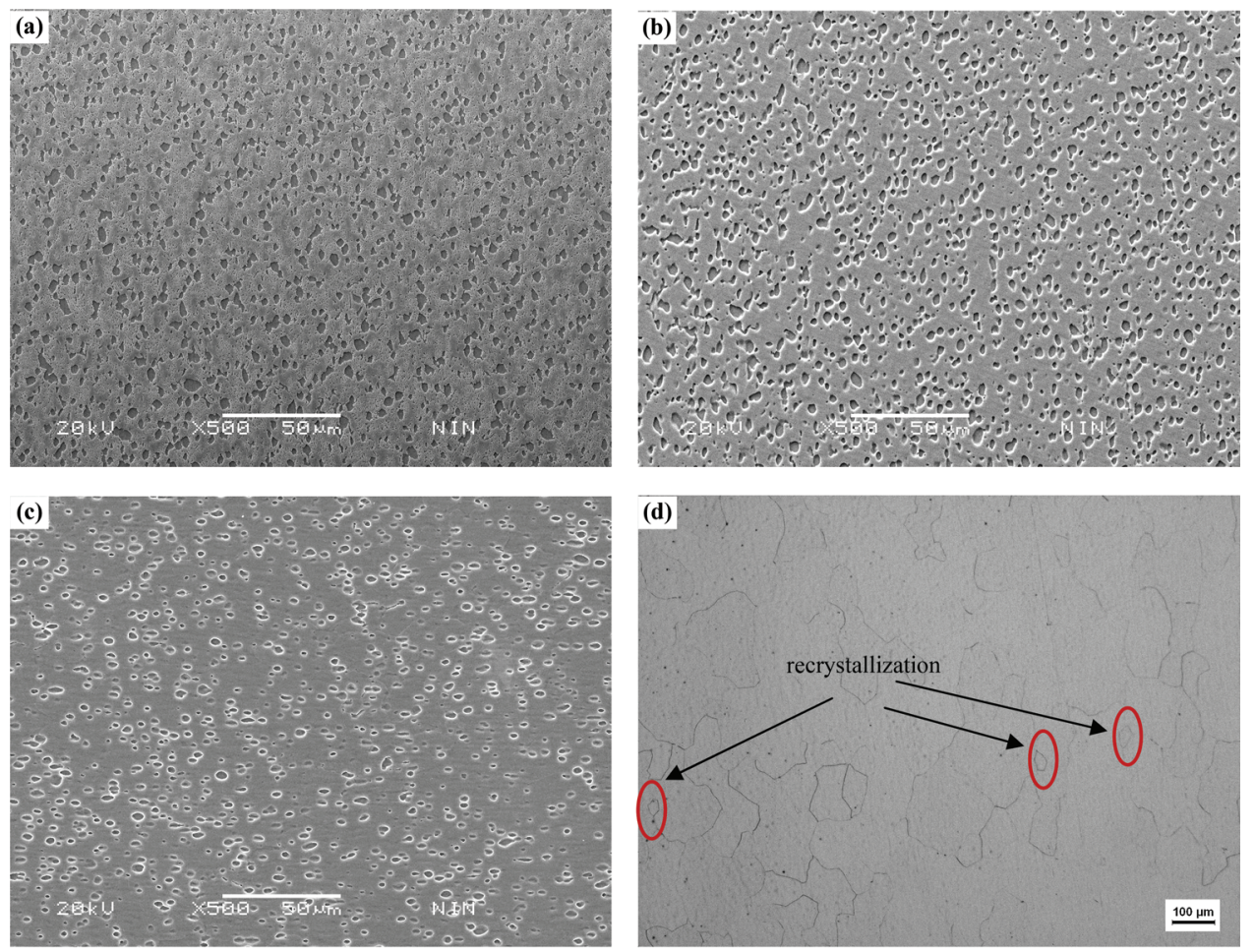

(e)

Figure 13: Microstructure of Ti555211 alloy at the strain rate of $0001 \mathrm{~s}^{-1}$ : (a) $750^{\circ} \mathrm{C}$; (b) $800^{\circ} \mathrm{C}$; (c) $850^{\circ} \mathrm{C}$; (d) $900^{\circ} \mathrm{C}$; (e) $950^{\circ} \mathrm{C}$. 

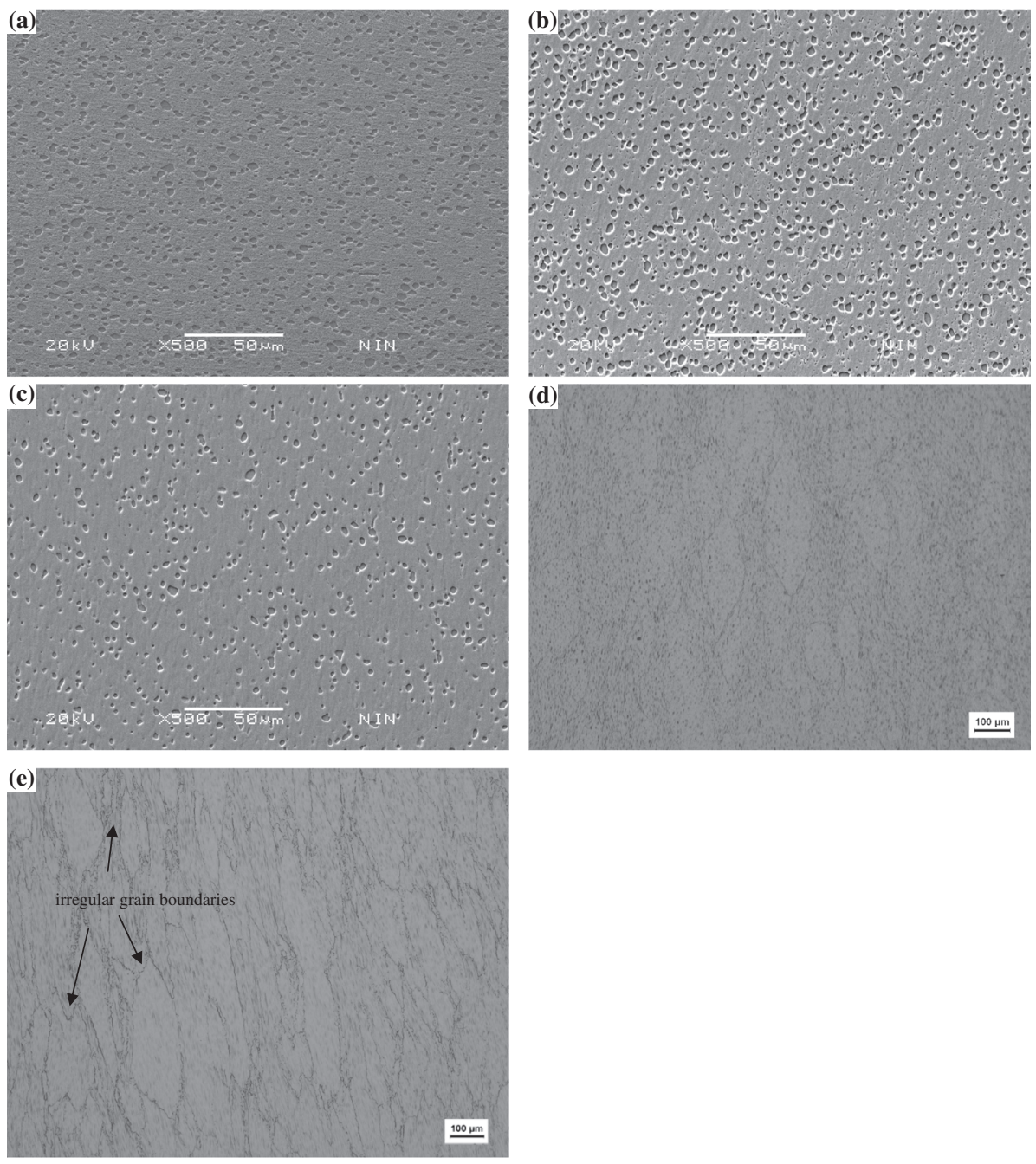

secondary $\alpha$ phase [38]. The TEM images in Figure 15 reveal the large number of dislocations and dislocation cells, which are generated during hot deformation of Ti555211 alloy; the interaction between dislocations also leads to a ridged structure (Figure 15(a), 15(b)). These dislocation substructures interact with and consume other dislocations continuously, thereby resulting in an increase in the misorientation of the subgrain boundary. Furthermore, subgrain boundaries are continuously transformed to HAGBs and form new subgrains (Figure 15(c)). Elongated $\beta$ grains with irregular grain boundaries are a typical feature of DRV. However, high strain rates hinder DRX since there is not enough time for the dislocations to be continuously consumed or generated.

Figures 16-18 compare, via grain boundary orientation maps, the misorientation angle distributions of the grain boundaries, under various hot deformation conditions. As the figures show, compared to that of the initial microstructure, the fraction of subgrain boundaries decreases gradually increasing deformation. Moreover,
Figure 14: Microstructure of Ti555211 alloy at the strain rate of $1 \mathrm{~s}^{-1}$ : (a) $750^{\circ} \mathrm{C}$; (b) $800^{\circ} \mathrm{C}$; (c) $850^{\circ} \mathrm{C}$; (d) $900^{\circ} \mathrm{C}$; (e) $950^{\circ} \mathrm{C}$.

the fraction of subgrain boundaries and LAGBs decreases gradually with increasing temperature and decreasing strain rate. Some of the subgrain boundaries and LAGBs also became HAGBs.

Figures 17 and 18 show the misorientation angle distributions of the grain boundaries in the $\alpha$ and $\beta$ phase, respectively. Deformation conditions of $750^{\circ} \mathrm{C}$, $0.001 \mathrm{~s}^{-1}$ (Figures 17(a) and 18(a)) and $800^{\circ} \mathrm{C}, 0.001 \mathrm{~s}^{-1}$ (Figures 17(b) and 18(b)) resulted in a decrease (from $29.5 \%$ to $15.7 \%$ ) in the fractions of HAGBs in the $\alpha$ phase; the fractions of HAGBs in the $\beta$ phase decreased significantly due to the partial dissolution of the secondary $\alpha$ phase and the growth of the $\beta$ grains.

As Figures $17(\mathrm{~b})$ and $18(\mathrm{~b})\left(800^{\circ} \mathrm{C}, 0.001 \mathrm{~s}^{-1}\right)$ and Figures $17(\mathrm{c})$ and $18(\mathrm{c})\left(800^{\circ} \mathrm{C}, 1 \mathrm{~s}^{-1}\right)$ show, the fractions of HAGBs in the $\alpha$ and $\beta$ phases decrease from $15.7 \%$ to $4.8 \%$ and change only slightly, respectively. This decrease results mainly from the subgrain boundaries in the $\alpha$ phase not having sufficient time, at a strain rate of $1 \mathrm{~s}^{-1}$, to absorb dislocations, for transformation to 

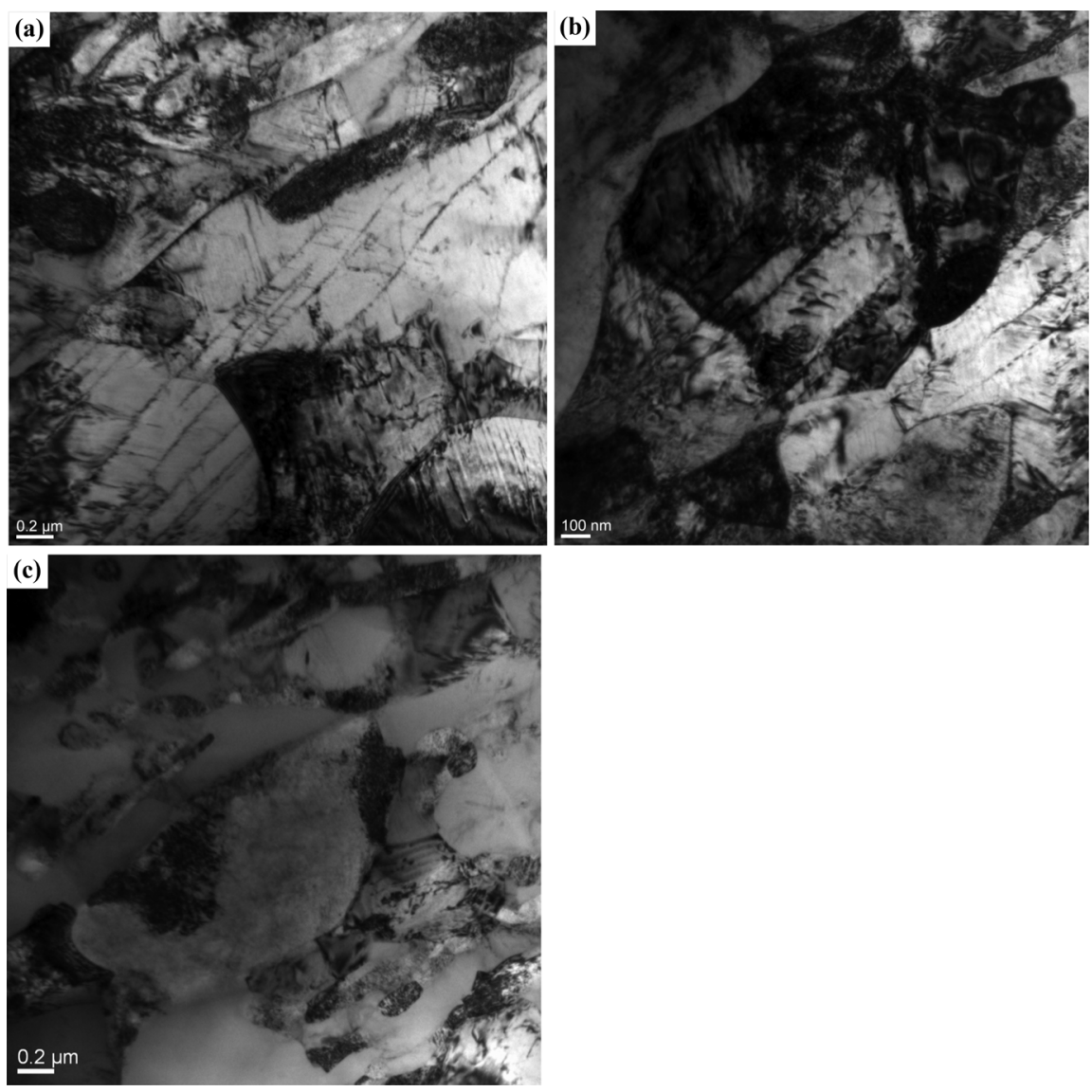

Figure 15: TEM observation of the deformation microstructure: (a) and (b) dislocation glide; (c) subgrain.

HAGBs. The fraction of HAGBs increased substantially for deformation conditions of $950^{\circ} \mathrm{C}, 0.001 \mathrm{~s}^{-1}$ (Figure $18(d))$, thereby resulting in an increased number of nucleation sites; this increased number of nucleation sites resulted in intense DRX.

\section{Conclusions}

In this study, Ti555211 titanium alloys were isothermally compressed to a height reduction of $50 \%$ at deformation temperatures and strain rates of $750-950^{\circ} \mathrm{C}$ and $0.001-1 \mathrm{~s}$ ${ }^{-1}$, respectively; the temperature was increased in $50^{\circ} \mathrm{C}$ intervals. EBSD and TEM were used to examine the grain boundaries and the substructure of the specimens after hot deformation. The following conclusions can be drawn from this investigation:

(1) The strain rate and deformation temperature have significant influences on the flow stress of Ti555211 alloy during isothermal deformation. The flow decreases with increasing deformation temperature or decreasing strain rate, and vice versa. Discontinuous yielding of Ti555211 alloy during high-temperature deformation is explained by the dynamic theory; the severity of discontinuous yielding increases with increasing deformation temperature.

(2) The average activation energy, $Q_{\text {ave }}$, of the alloy was determined using the nonlinear regression method and a hyperbolic sine equation to describe the relationship among the stress, strain rate, and deformation temperature; Activation energies of hot deformation were calculated in 0.05 intervals for strains ranging from 0.1 to 0.7 . For example, the respective values of $476.557 \mathrm{~kJ} / \mathrm{mol}$ and $222.173 \mathrm{~kJ} / \mathrm{mol}$ (at a strain of 0.1 ) were obtained for the $(\alpha+\beta) \beta$ region.

(3) The predictive capability of the developed constitutive equation was quantified in terms of $R$ and the AARE. The determined $R$ and AARE values of 0.99084 and 6.914\%, respectively, for the Arrhenius-type constitutive model, are indicative of the good prediction capabilities of the developed strain-compensated constitutive equation.

(4) At high strain rates, there is insufficient time for continuous annihilation or generation of dislocations and hence DRX is difficult in the $\beta$ phase. In the case of the $\alpha+\beta$ phase, the strain rate has little 

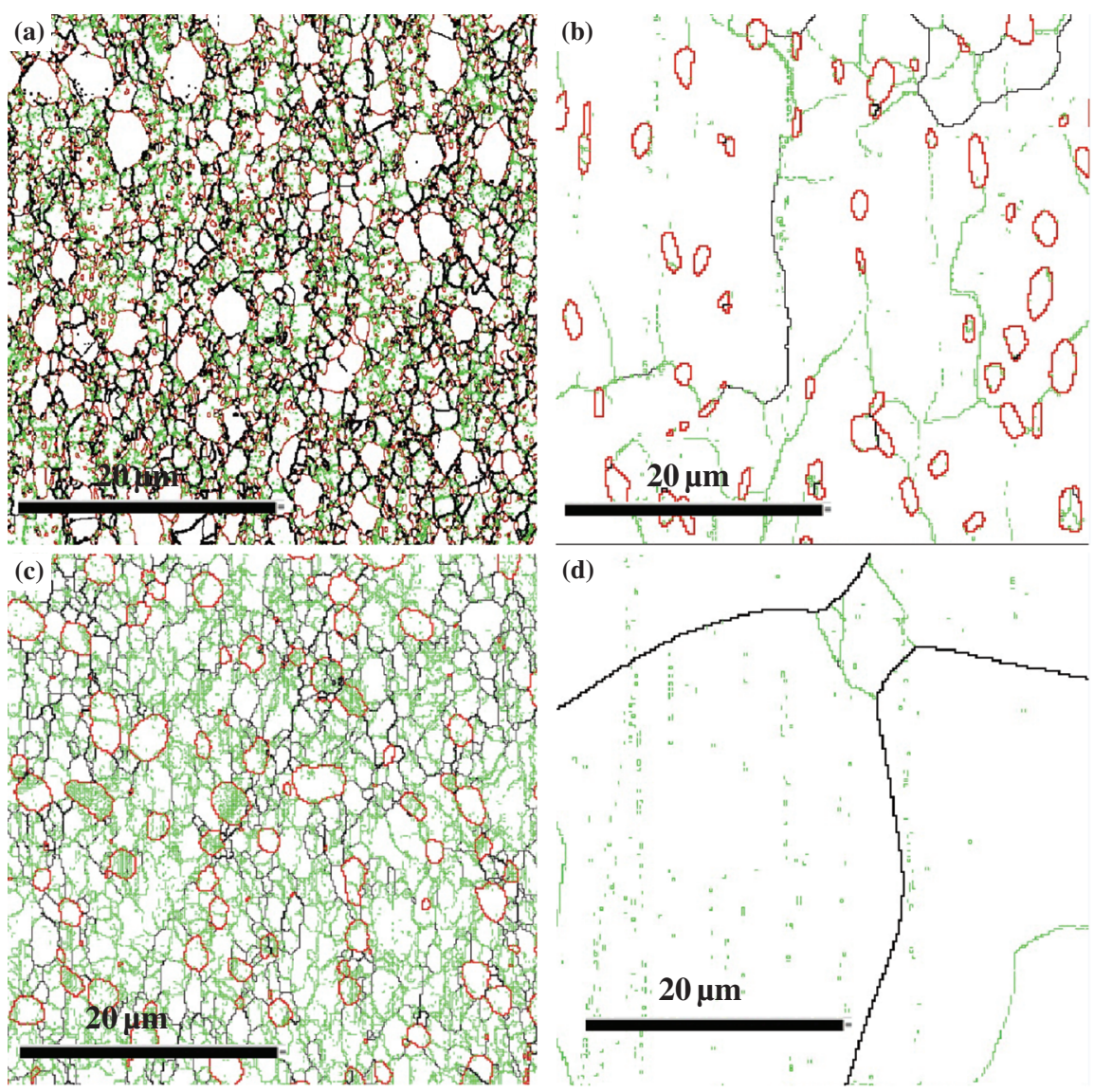

Figure 16: The grain boundary orientation map of Ti555211 alloy after hot deformation: (a) $750^{\circ} \mathrm{C}, 0.001 \mathrm{~s}^{-1}$; (b) $800^{\circ} \mathrm{C}, 1 \mathrm{~s}^{-1}$; (c) $800^{\circ} \mathrm{C}$, $0.001 \mathrm{~s}^{-1}$; (d) $950^{\circ} \mathrm{C}, 0.001 \mathrm{~s}^{-1}$.

(a)

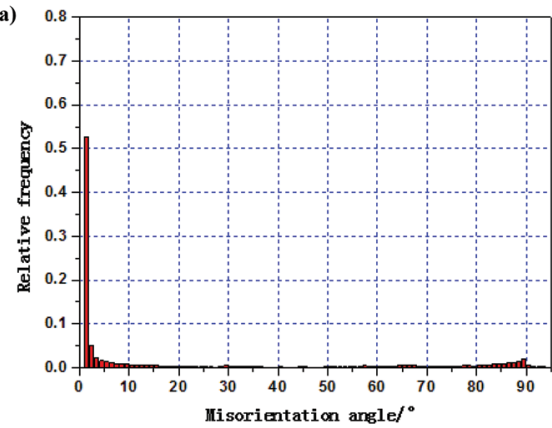

(b)

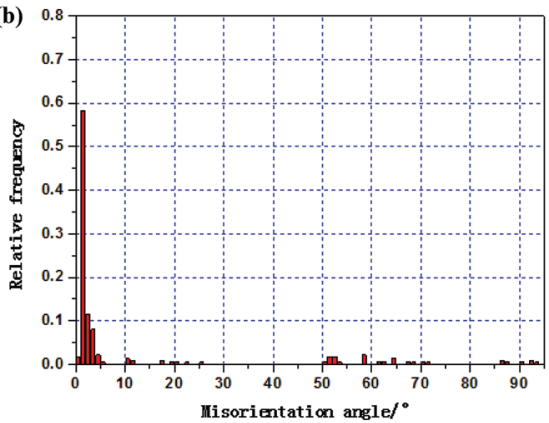

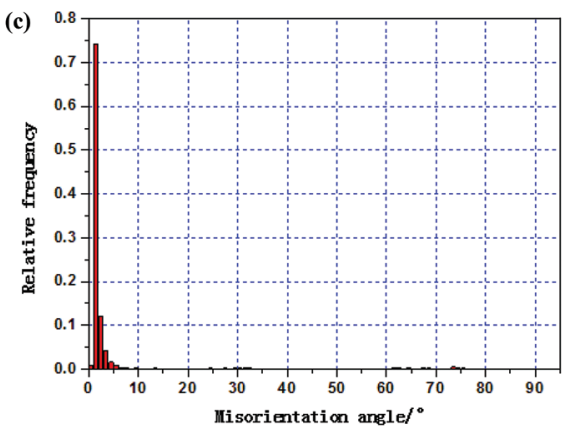

Figure 17: Distribution of grain boundary misorientation angles ( $\alpha$ phase): (a) $750^{\circ} \mathrm{C}, 0.001 \mathrm{~s}^{-1}$; (b) $800^{\circ} \mathrm{C}, 0.001 \mathrm{~s}^{-1}$; (c) $800^{\circ} \mathrm{C}, 1 \mathrm{~s}^{-1}$. 

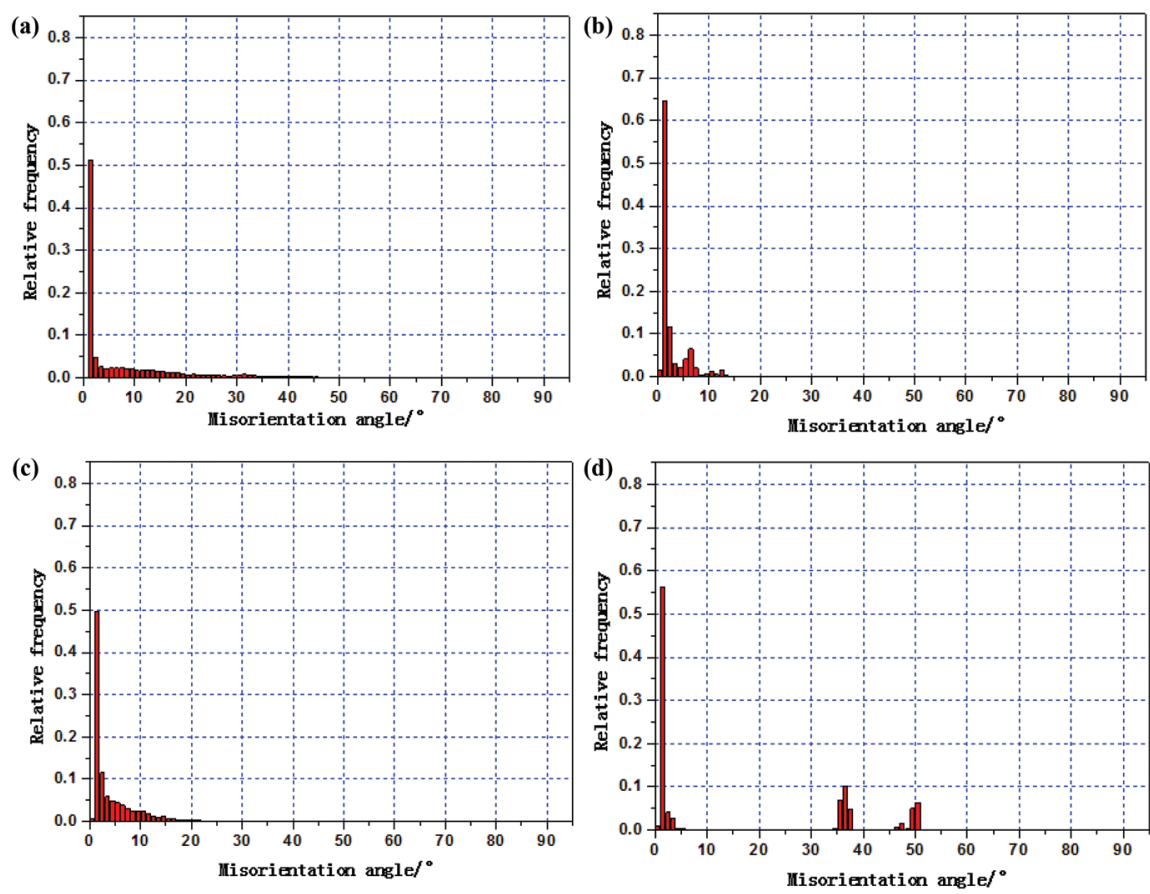

Figure 18: Distribution of grain boundary misorientation angles ( $\beta$ phase): (a) $750^{\circ} \mathrm{C}$, $0.001 \mathrm{~s}^{-1}$; (b) $800^{\circ} \mathrm{C}, 0.001 \mathrm{~s}^{-1}$; (c) $800^{\circ} \mathrm{C}, 1 \mathrm{~s}^{-1}$ (d) $950^{\circ} \mathrm{C}, 0.001 \mathrm{~s}^{-1}$.

impact on the morphology of the primary $\alpha$ phase, but has some effect on the morphology, and fraction, of the secondary $\alpha$ phase formed. Furthermore, the fraction of primary $\alpha$ phase decreases with increasing deformation temperature.

Funding: This research work was supported by the Project of Introducing Talents of Discipline to Universities ("111" Project No. B08040).

\section{References}

[1] S.K. Kar, S. Suman, S. Shivaprasad, A. Chaudhuri and A. Bhattacharjee, Mater. Sci. Eng.: A, 610 (2014) 171-180.

[2] A.-F. Gerday, M. Ben Bettaieb, L. Duchêne, N. Clément, H. Diarra and A. Habraken, Acta Mater., 57 (2009) 5186-5195.

[3] N. Jones and M. Jackson, Mater. Sci. Technol., 27 (2011) 1025-1032.

[4] N. Jones, R. Dashwood, D. Dye and M. Jackson, Metall. Mater. Trans. A, 40 (2009) 1944-1954.

[5] G.-Z. Quan, D.-S. Wu, G.-C. Luo, Y.-F. Xia, J. Zhou, Q. Liu and L. Gao, Mater. Sci. Eng.: A, 589 (2014) 23-33.

[6] G. Dessein, V. Wagner, M. Baili and D. Lallement, Key Eng. Mater., 446 (2010) 147-155.

[7] S.K. Kar, A. Ghosh, N. Fulzele and A. Bhattacharjee, Mater. Character, 81 (2013) 37-48.

[8] M. Jackson, N. Jones, D. Dye and R. Dashwood, Mater. Sci. Eng.: A, 501 (2009) 248-254.

[9] N. Jones, R. Dashwood, D. Dye and M. Jackson, Mater. Sci. Eng.: A, 490 (2008) 369-377.
[10] Z. Yinghui, G. Peng, Y. Guanjun, Z. Yongqing and M. Xiaonan, Rare Metal Mater. Eng., 38 (2009) 550-553.

[11] F. Warchomicka, C. Poletti and M. Stockinger, Mater. Sci. Eng.: A, 528 (2011) 8277-8285.

[12] X. Zhang, H. Kou, J. Li, F. Zhang and L. Zhou, J Alloys Compd., 577 (2013) 516-522.

[13] J.C. Fanning, J. Mater. Eng. Perform., 14 (2005) 788-791.

[14] X.U. Feng, J.I. Bo, Y.F. Zhu, Y.X. Luo and K.C. Peng, Chin. J. Nonferrous Metals, 20 (2010) 100-103.

[15] X. Wang, J. Liu, J. Lei, M. Cao and Y. Liu, Acta Metall. Sin. (China), 43 (2007) 1129-1137.

[16] Y. Fu, Y. Song, S. Hui et al., Chin. J Rare Metals, 33 (2009) 92-95.

[17] Y. Yang, W. Wang, B. Ma, Z. Wen, Y. Wang and H. Ma, Rare Metals Lett., 26 (2007) 32-34.

[18] Q. Wang, Q. Zhang, Y. Chen, X. Ju, S. Wei, D. Wang, Z. Shi, Q. Gao and J. Song, J. Mater. Eng., 11 (1996) 17-21.

[19] Y. Zhao, H. Qu, L. Feng, H. Yang, Y. Zhang, H. Guo and D. Huang, Titan. Ind. Progress, 21 (2004) 22-24.

[20] Y.J. Ma, D.C. Wang, H.W. Wang, J.F. Lei, J. Wang, Y.Y. Liu, Q. Gao and R. Yang, Chin. J. Nonferrous Metals, 20 (2010) 414-418.

[21] S.L. He, X.J. Lei, X.X. Wang et al., Chin. J. Nonferrous Metals, 20 (2010) 43-47.

[22] W. Zhang, C. Cao, X. Li, J. Ma and Z. Zhu, Rare Metal Mater. Eng., 34 (2005) 549-551.

[23] M. Onsøien, Ø. Gundersen, Ø. Grong and T. Skaland, Metall. Mater. Trans. A, 30 (1999) 1053-1068.

[24] M. Onsøien, Ø. Gundersen, Ø. Grong and T. Skaland, Metall. Mater. Trans. A, 30 (1999) 1069-1079.

[25] R. Ding and Z. Guo, Mater. Sci. Eng.: A, 365 (2004) 172-179.

[26] T. Seshacharyulu, S. Medeiros, W. Frazier and Y. Prasad, Mater. Sci. Eng.: A, 325 (2002) 112-125.

[27] H. Matsumoto, M. Kitamura, Y. Li, Y. Koizumi and A. Chiba, Mater. Sci. Eng.: A, 611 (2014) 337-344. 
[28] I. Weiss and S. Semiatin, Mater. Sci. Eng.: A, 243 (1998) 46-65.

[29] G. Ji, F. Li, Q. Li, H. Li and Z. Li, Mater. Sci. Eng.: A, 528 (2011) 4774-4782.

[30] G.-Z. Quan, W.-Q. Lv, Y.-P. Mao, Y.-W. Zhang and J. Zhou, Mater. Des., 50 (2013) 51-61.

[31] A. Pramanik, Int. J. Adv. Manuf. Technol., 70 (2014) 919-928.

[32] C. Liu, X. Tian, H. Tang and H. Wang, J Alloys Compd., 572 (2013) 17-24.

[33] S. Raghunathan, R. Dashwood, M. Jackson, S. Vogel and D. Dye, Mater. Sci. Eng.: A, 488 (2008) 8-15.
[34] X. Ma, W. Zeng, Y. Sun, K. Wang, Y. Lai and Y. Zhou, Mater. Sci. Eng.: A, 538 (2012) 182-189.

[35] R. Kapoor, D. Pal and J. Chakravartty, J. Mater. Process. Technol., 169 (2005) 199-205.

[36] R. Whittaker, K. Fox and A. Walker, Mater. Sci. Technol., 26 (2010) 676-684.

[37] J. Fanning, J. Mater. Eng. Perform, 14 (2005) 788-791.

[38] N. Wain, X. Hao, G. Ravi and X. Wu, Mater. Sci. Eng.: A, 527 (2010) 7673-7683. 